\title{
Fotografia e experiência: A perda de si como método no processo criativo
}

\section{Daniela Tavares Paoliello'}

Resumo: Propõe-se neste artigo refletir sobre a experiência de "perda de si" enquanto método no processo criativo contemporâneo, em específico naqueles que envolvem a fotografia. A perda de si é pensada a partir da relação entre corpo e espaço, e a autoperformance para a câmera, centrando a discussão na série fotográfica Escavar o escuro, desenvolvida em trabalho de campo no litoral pacífico mexicano entre 2019 e 2020 pela autora.

Palavras-chave: Fotografia. Perda. Metodologia. Corpo.

\section{Photography and experience: The loss of self as method in the creative process}

\begin{abstract}
This article proposes to reflect on the experience of "loss of self" as a method in the contemporary creative process, specifically in those involving photography. The loss of self is worked from the relationship between body and space, and the self-performance for the camera, focusing the discussion on the photographic series Escavar o Escuro, developed in fieldwork on the Mexican Pacific coast between 2019 and 2020 by the author.
\end{abstract}

Keywords: Photography. Loss. Methodology. Body.

I Daniela Paoliello é artista visual e doutora em Artes pelo PPGARTES, UERJ. Autora dos livros Exílio e Que horas são no paraíso? Nos últimos anos vem desenvolvendo sua pesquisa em torno da experiência da perda de si como método no processo criativo fotográfico. E-mail: danielapaoliello@gmail.com; ORCID: https://orcid.org/0000-0003-23468397. Lattes iD: http://lattes.cnpq.br/5413528453662736; Belo Horizonte, Brasil. 


\section{Introdução}

A produção de diversos artistas contemporâneos é atravessada por procedimentos que combinam intencionalidade e descontrole, método e nãosaber, explorando a potente contradição de se produzir premeditadamente experiências de risco, descontrole e abertura às afecções do mundo. Trabalhos que são produzidos a partir de um projeto calculado, com pontos de partida precisos e territórios delimitados ao mesmo tempo que apontam para uma abertura à experiência da "perda de si".

Proponho neste artigo desenvolver, em um primeiro momento, a ideia de experiência da "perda de si" enquanto método no processo criativo contemporâneo. Para, em um segundo momento, desenvolver uma discussão em torno da série fotográfica Escavar o Escuro, de minha autoria, produzida entre 2019 e 2020, em Água Blanca, Oaxaca, na costa pacífica mexicana. Parte-se, aqui, da hipótese de que a intencionalidade de se colocar em risco e produzir um deslocamento (físico e epistêmico) - presente em diversos trabalhos na contemporaneidade ${ }^{1}$ - pode ser utilizada como método no processo criativo.

A "perda de si" é compreendida aqui como um deslocamento referencial de um lugar de enunciação em que o sujeito está situado. Experiência, portanto, que desloca o indivíduo de suas zonas de conforto e, a partir desse distanciamento, o coloca em risco ao desconstruir noções préafirmadas de indivíduo e identidade (PAOLIELLO, 2020). Nessas experiências intencionalmente disparadas, ele vivencia a desconstrução de suas certezas, de sua percepção do mundo e de si mesmo, experimentando um abalo em sua episteme. É nesse sentido que coloca em jogo a própria subjetividade como forma de se expor ao diálogo permanente.

Essa perda implicaria, portanto, na renúncia - mesmo que parcial - do domínio de si, abrindo o indivíduo às forças do mundo. Experiência autoperturbadora, que põe o sujeito em questão, que desestabiliza o ser e o desloca de seus espaços afirmados, de seu lugar de pertencimento, desconstruindo e expandindo os caminhos usuais do pensamento poético, ético e estético. Como afirma Paulo Herkenhoff: "a arte pode nos fazer pensar sobre a perda. E essa é sua potencialidade política mais radical" (HERKENHOFF, 2011).

1 Marina Abramovic, Yoko Ono, Chris Burden, Ana Mendieta, Hannah Wilke, Francesca Woodman, Rebecca Horn, Juliana Notari, Marise Maués, Regina Galindo, Rodrigo Braga, Priscilla Rezende, Carlos Martiel, Paulo Nazareth, etc. 
A experiência da "perda de si" seria, então, tudo aquilo que retira o indivíduo do espaço - físico/material ou simbólico - que seu corpo habita, seja a partir do deslocamento espacial, do encontro com o "outro", das práticas de jogo ou de situações intencionalmente criadas, onde o artista abre mão do controle e se expõe às forças externas para desencadear a produção artística. Ele cria, portanto, a partir de uma proposta metodológica que combina rigor e descontrole, trabalhando a partir de uma negociação constante com essas forças (MENEZES, 2020).

A "perda de si" não envolve apenas uma passagem filosófica ou intelectual, mas acima de tudo se dá como uma experiência que solicita a matéria, o sensório, e que coloca o corpo em questão. Essa perda não é simplesmente a destruição, o aniquilamento, mas está ligada a um ganho, a um desejo de desconstrução e criação que se dá pela mediação do corpo. É aquilo que nos marca com uma diferença e que vem, de repente, desmentir nossa construção do mundo, fazendo, ainda que minimamente, com que desabem. É desse lugar que a fotografia pode atuar como construtora de experiências, como dispositivo capaz de desencadear acontecimentos, produzir o real e não apenas registrá-lo.

É nesse sentido que a tese desenvolvida pelo fotógrafo e pesquisador Ronaldo Entler figura como um exemplo importante, na medida em que faz um estudo em torno do "acaso" na fotografia investigando a abertura da prática criativa ao erro, o qual poderia, segundo o autor, apontar para novos caminhos implicando um certo descontrole intencional do artista sobre seu processo.

É importante também citar aqui o livro da escritora Ana Kiffer intitulado A perda de si (2017), onde são publicadas cartas, datadas do início do século XX, do poeta e dramaturgo Antonin Artaud. No prefácio às cartas, Kiffer afirma que Artaud apostava incessantemente no desfazer dele mesmo, e que o "perder de si" era muitas vezes o único caminho para se reconfigurar subjetivamente. Esse desfazer de si aconteceria em Artaud a partir de uma experiência de "erosão do pensamento", e do "abandono do espírito", que deslocaria a atividade da escrita para um conjunto de sensações da carne e não mais para o que entenderíamos ser a coerência e destreza do intelectivo ou do mental (KIFFER in ARTAUD, 2017).

O termo "desilha" ou "desilhar-se" é outro exemplo interessante de proposição conceitual que envolve, em alguma medida, a experiência da "perda de si" no processo criativo contemporâneo. "Desilha" dá nome à 
plataforma de pesquisa e ação em arte na cidade ${ }^{2}$, desenvolvida por Lívia Flores, Ronald Duarte e Michelle Sommer dentro do programa de pósgraduação da UFRJ. No texto Desilha em Três Vistas (2019), que integra o livro Cadernos Desilha 2, acompanhamos uma conversa entre os três pesquisadores, que aponta para práticas artísticas de deslocamento físico e mental como impulso para criar.

Nessa conversa Sommer fala de uma "espontaneidade produzida". Afirma que desilhar-se seria como pular do abismo: "Desilha intenciona deslocar o artista de sua zona de conforto, confrontá-lo a partir de estratégias, e colocá-lo em relação, seja a algo ou alguém" (SOMMER, et. al, p.28, 2019). Ronald Duarte sugere que esse desilhar-se seria como "pisar no abismo, no acaso, naquilo que não sei" (DUARTE, et. al., p.28, 2019). E observa como os artistas tendem a entrar em uma zona de conforto, de criar procedimentos poéticos próprios e não se deslocarem daí. O projeto Desilha intenciona provocar essa saída de si, propondo "uma nova forma de pensar a Arte. Não mais pelas bolhas, conceitos estabelecidos, prontos e com muitas certezas" (DUARTE, et. al in FLORES; SOMMER org., p.29, 2019).

Como afirmam ainda Flores e Sommer no artigo Derivas acadêmicas em pósgraduação em artes na cidade do Rio de Janeiro, desilha seria um "convite ao reconhecimento de estar-em-situação-de-ilha, logo, à sua desnaturalização" (FLORES; SOMMER, 2019). Os contornos da ilha entendidos como aquilo que interrompe uma continuidade com o contexto. Convidam, portanto, a um descentramento de si, ao gesto de deslocar-se, a fazer movimentos de travessia. ${ }^{3}$

2 "Desilha é uma plataforma de pesquisa e ação em arte e cidade, que inclui projeto de pesquisa e cursos regulares oferecidos pelo Programa de Pós Graduação em Artes Visuais (PPGAVEBA-UFRJ), sediado na llha do Fundão, onde se localiza a cidade universitária. O histórico da construção deste campus universitário reflete as dificuldades de assentamento e concretização do lugar da educação no Brasil, oscilando entre projeto oligárquico e regime autoritário, utopia e inacabamento. Reconhecendo a potência da universidade pública e gratuita como lugar de trocas e amplas transformações hoje, Desilha expande-se e toma a cidade como palco para a construção de narrativas avessas à normatividade acadêmica, em uma cidade violentamente impactada pelo desmonte de políticas públicas e pelas consequências das reformas urbanas ocorridas entre a realização dos megaeventos Copa do Mundo (2014) e Olimpíadas (2016). Nessa direção, restaura forças vitais para empreender novas travessias em tempos de crise e ameaças à democracia no Brasil." (FLORES, Lívia; SOMMER, Michelle. Derivas acadêmicas em pós-graduação em artes na cidade do Rio de Janeiro. REVISTA POIÉSIS, Niterói, v. 20, n. 33, p. 217-236, jan/jun. 2019).

3 Ressalto também a tese defendida pela artista e pesquisadora Thais Graciotti intitulada Viagem a um arquipélago possível: o artista viajante em processo, onde discorre sobre o deslocamento, em específico, a "viagem" como elemento central no processo criativo de alguns artistaś contemporâneos, que empregam, portanto, sempre o mesmo recurso - o do deslocamento territorial - para desencadear seus trabalhos. 
É nesse sentido também que a "perda de si" é pensada aqui, como experiência de deslocamento que pode ser intencionalmente desencadeada. Esse descentramento aqui denominado como "perda de si" é capaz de não apenas impulsionar um estado de invenção, como dar conta de uma dimensão crítica e política desse estado que exige do sujeito um distanciamento epistemológico das estruturas dominantes que o constituem. A "perda de si" é, portanto, mais do que uma desmedida, o deslocamento de uma medida, de um território, de um lugar de enunciação. Ela é um deslocamento do próprio eu.

Silvia Federici em sua obra Calibã e a Bruxa (2017), comenta a implementação de um programa de "domínio de si" na passagem do feudalismo para o capitalismo, impulsionado pelo racionalismo científico que intencionava transformar o corpo em uma máquina laboral. A valorização da razão em detrimento de um saber do corpo funcionava no sentido de deslegitimar epistemologias pautadas em paradigmas não-científicos, nomeando-as como infantis, primitivas, enganosas e irracionais. Foram várias as regras implementadas de forma autoritária e violenta nesse momento para moldar uma ideia de corpo submetido à razão, onde as paixões, o sensorial e o desejo deveriam ser eliminados. Essa mecanização do corpo e a hegemonização epistemológica foram cruciais para o programa de "domínio de si".

O projeto de caça às bruxas é produzido através de um ataque feroz e constante ao corpo, atentando contra a visão mágica do mundo - que imperava entre grande parte da sociedade - e consolidando a imagem do homem selvagem que habita os países colonizados, recém invadidos.

\footnotetext{
O saber apenas pode converter-se em poder se conseguir fazer cumprir suas prescrições. Isto significa que o corpo mecânico, o corpo-máquina, não poderia ter se convertido em modelo de comportamento social sem a metódica - encontramos um ataque feroz ao corpo, firmemente apoiado por muitos do que subscreviam a nova doutrina e contra a visão mágica do mundo que, apesar dos esforços da Igreja, seguia predominante em escala popular durante a Idade Média. O substrato mágico formava parte de uma concepção animista da natureza que não admitia nenhuma separação entre a matéria e o espírito, e deste modo imaginava o cosmos como um organismo vivo, povoado de forças ocultas, de onde cada elemento estava em relação favorável com o resto (FEDERICI, pos. 4543 de 8703, 2017).
}

Ainda que tenha enfrentado extraordinária resistência, essa perseguição sistemática logrou reduzir a noção de "corpo como receptáculo de poderes 
mágicos" (que havia predominado no mundo medieval) ${ }^{4}$ na primeira e principal máquina capitalista. O programa de "domínio de si" moldou o corpo moderno a partir da implementação de diversos mecanismos de controle e da eliminação de saberes não associados à razão cientificista.

A história da "perda de si" no processo criativo parece bem difícil de traçar, uma vez que o desejo de criar a partir do deslocamento físico ou epistêmico parece remontar a um contexto histórico mais remoto, que nos leva aos artistas viajantes, aos observadores da natureza, aos que se exilaram em ilhas em busca de inspiração. Na história moderna encontramos figuras como Arthur Rimbaud e Antonin Artaud, que tinham seu processo de criação literário fincado em experiências que implicavam a "perda de si". O artista pós-impressionista, Paul Gauguin que, movido pela fantasia primitivista, decide viver nas ilhas do pacífico a fim de desfazer-se de sua vida burguesa e encontrar inspiração criativa. Observamos também Georges Bataille e seus companheiros do visceral projeto Acéphale, que em um de seus rituais chegam a ponto de quase sacrificar um homem; já seu contemporâneo, Michel Leiris parte em expedição à África na busca de reinventar-se, em uma prática de perda e autoanálise no encontro com a alteridade cultural.

Se mirarmos as vanguardas artísticas do início do século XX identificamos também uma série de práticas que, a partir da implicação do corpo, partem do fazer intencionado de perder-se, propondo uma metodologia que tem como intuito produzir deslocamentos radicais, subverter possíveis roteiros e se abrir para a experiência radical da exterioridade (FONTCUBERTA, Joan. 2012, pos. 148 de 3148). Em Artificial Hells, Claire Bishop aponta o futurismo e o dadaísmo, entre os primeiros grupos a articularem propostas de participação do público e fluxos entre arte e vida no início do século $X X$. Nas performances futuristas, a interação baseava-se em despertar a energia agressiva do público e se dava, muitas vezes, através de provocações direcionadas aos mesmos, desencadeando situações de total descontrole. Buscavam provocar o conflito: passar cola na cadeira onde as pessoas se sentariam; vender um mesmo lugar para várias pessoas; dar ingressos gratuitos a indivíduos notavelmente "desequilibrados" ou "excêntricos"; espalhar poeira nas cadeiras para desencadear espirros e tosses.

Já as excursões dadaístas, propunham passeios turísticos em Paris a locais "qui non pas raison d'exister" ("que não tem razão de existir"), isto é, 
segundo os guias de turismo, desconhecidos e sem relevância histórica ou sentimental. Esses passeios a lugares banais se afirmavam em oposição à lógica desses guias, em contra-senso ao circuito dos monumentos, parques e museus. Para atrair o público divulgavam panfletos com conteúdo falso, como demonstra Bishop: "O folheto também listava uma série de futuras visitas propostas - que de fato nunca seriam realizadas - para destinos como o Louvre, o parque em Buttes Chaumont e a Gare Saint-Lazare" ${ }^{5}$ (BISHOP, 2012). Opostos à lógica e à postura racionalista, os dadaístas propunham um mover-se espontâneo, traçando deslocamentos territoriais e desestabilizando os percursos tradicionais para se conhecer uma cidade.

Esses movimentos experimentais de abertura ao acaso e à perda operados pelas vanguardas históricas também vão repercutir na prática fotográfica da época, sobretudo no fazer de artistas surrealistas ${ }^{6}$, que questionaram de forma bastante contundente a fotografia objetiva, desafiando a lógica racionalista e tecnicista da época. A abertura ao acaso, ao erro e ao acidente marcam fortemente essa geração, que toma a câmera e o processo de revelação em sua abertura ao acontecimento e aos resultados inesperados, e não como instrumento preciso da ciência. Ou seja, a fotografia era considerada em sua qualidade ativa, sendo seus desvios incorporados no processo e não descartados como uma falha do mecanismo. E ainda, a câmera teria a potência de acolher os acasos, fossem eles provenientes do inconsciente ou dos acidentes do mundo com os quais o indivíduo se depararia em seus passeios fotográficos. Desse acolhimento surgiria não uma representação realista e direta do visível, mas uma criação ficcional. Rompiam, portanto, com a aproximação racionalista do fotográfico - que marcava sua época - reconhecendo sua força criativa.

Anne Brigman também é um exemplo interessantíssimo que precede os surrealistas e que figura como uma das primeiras artistas na história a aliar experiência, perda e fotografia utilizando-se da autoperformance para a câmera na natureza nos anos 1900. A experiência de "perda de si" afirma-se de forma contundente na obra de Brigman, uma vez que a artista não só transgredia radicalmente as convenções de sua época, utilizando-se de sua

5 Tradução livre. Texto original: The flier also listed a number of proposed future visits - which in fact would never be carried out - to destinations including the Louvre, the park at Buttes Chaumont and the Gare Saint- Lazare.

6 Claude Cahun, Dora Maar, Florence Henri, Hans Bellmer, Lee Miller, Man Ray, Maurice Tabard, René Magritte, entre outros. 
própria nudez, como colocava seu corpo em relações de experiência e risco no espaço, se negando a encerrar-se na esfera do privado.

É, porém, apenas na virada para o contemporâneo nas artes visuais - a partir dos anos 1950/60 - que ocorre uma mudança paradigmática a partir da qual a fotografia começa a ser amplamente explorada segundo outras perspectivas de uso e produção de subjetividade, e passa a ser reconhecida como um dispositivo com potência de invenção e intervenção direta no fluxo do real (PAOLIELLO, 2020). O que ocorre é o que Fontcuberta denomina de "desindexação" da imagem, em que a fotografia não está mais exclusivamente atrelada à memória ou ao objeto, e a representação do real dá lugar à construção de sentido. Quer dizer, a fotografia ganha uma espécie de agência. Desloca-se de um lugar autômato e é reconhecida em sua qualidade ativa, que nos permite reformulá-la como ação, como agenciadora de acontecimentos. E como lugar potente dessa perda, como um instrumento que desloca o corpo que o opera. São numerosos os exemplos de processos artísticos que são atravessados pela experiência de "perda de si" intencionalmente criada nesse momento. Podemos citar as famosas fotoperformances de Adrian Piper, Ana Mendieta, Chris Burden, Eikoh Hosoe, Francesca Woodman, Gina Pane, Hannah Wilke, Mary Beth Edelson, Rebecca Horn, entre outros. Na contemporaneidade também encontramos diversas práticas que envolvem a linguagem fotográfica e que podem ser lidas nessa chave. Destaco aqui os trabalhos de Carlos Martiel, Juliana Notari, Marise Maués, Paulo Nazareth, Rodrigo Braga, Regina Galindo, entre outros.

Essas práticas são exemplos que podem ser lidos a partir da chave da "perda de si". Práticas que informam significativamente sobre como a fotografia pode potencializar o processo criativo, com potência de não apenas registrar, mas também de desencadear os processos de criação, sobretudo aqueles que implicam o corpo em experiências de abalo e deslocamento de suas zonas de conforto. Ou seja, nos impulsiona a refletir sobre como a "perda de si" pode se dar a partir de uma convocação da experiência fotográfica.

A ruptura com o pensamento moderno, que marcou mais de 100 anos o fazer fotográfico, abre a linguagem a um uso que se volta a pensar sobre seu processo de produção, reconhecendo a presença de um sujeito por trás da confecção fotográfica, negando o "instante decisivo" e o pressuposto do fotógrafo caçador e invisível de Cartier Bresson (1952). O que nos permite refletir sobre a extensão dos agenciamentos que a fotografia produz, sobre seu potencial de desencadear experiências, criar relações e produzir acontecimentos, convocando o corpo a vivenciar situações que não seriam experimentadas sem a presença do mecanismo fotográfico. 
A percepção de que a fotografia possui uma natureza construtiva possibilita pensarmos o dispositivo fotográfico como um instrumento propositivo, uma forma de fundir-se no mundo, de estar presente não só praticando um olhar, mas produzindo e fazendo durar a experiência, intervindo diretamente nos espaços que atravessa. Nesse sentido, a dimensão da experiência se inscreve na fotografia não como produtora de saber, mas como catalisadora do acontecimento em si e da construção narrativa. É a partir dessa perspectiva que a série Escavar o Escuro, apresentada a seguir, se constitui.

\section{Escavar o escuro}

O que és deve à atividade que une os inúmeros elementos que te compõem, à intensa comunicação desses elementos entre si. São contágios de energia, de movimento, de calor, ou transferências de elementos que constituem interiormente a vida do teu seu orgânico. (Georges Bataille)

É 2020, janeiro, Agua Blanca, Oaxaca, costa pacífica mexicana.

Fotografar sem ver a cena. Trabalho com uma "dupla cegueira". Não ver pelo gesto de tornar-se objeto da própria captura, dar-se à câmera como imagem, perder o controle do olhar. E não ver por uma questão ótica, pela ausência de luz. Processo escultórico negativo de escavar uma forma no escuro. Fotografar cenas que apenas a câmera é capaz de revelar, que o olho não alcança. "Escavar, abrir as formas visíveis" (DIDI-HUBERMAN, 2015, p. 380).

Caminho pela praia buscando resquícios de brilho, pontos de luz que emanam do espaço: uma cidade distante se mistura ao céu na linha do horizonte; escamas de peixe jogadas sobre a areia refletem a escassa luz de um restaurante ainda aberto à beira mar; uma lanterna de pescadores se move do alto das ilhotas; a espuma das ondas se dissipa; estrelas cadentes rasgam o céu, Sirius, o Cinturão de Orion, Canopus; plânctons bioluminescentes; lua cheia, lua minguante, lua nova. 50 noites de praia. Sigo coletando o impalpável.

Nas imagens da série vemos rasgos de luz que atravessam o escuro, anunciando algo. A luz do espaço, estelar, projetando-se na direção da câmera, e alcançando o corpo, contrariando sua vocação de nunca nos alcançar. "O horizonte quase se dissolve, o céu e a terra se confundem e tornam-se espaços intercambiáveis" (ENTLER, 2017).

A ausência de luz se afirma com uma qualidade ativa que, segundo a neurofisiologia, é capaz de desinibir as off-cells, células da nossa retina, 


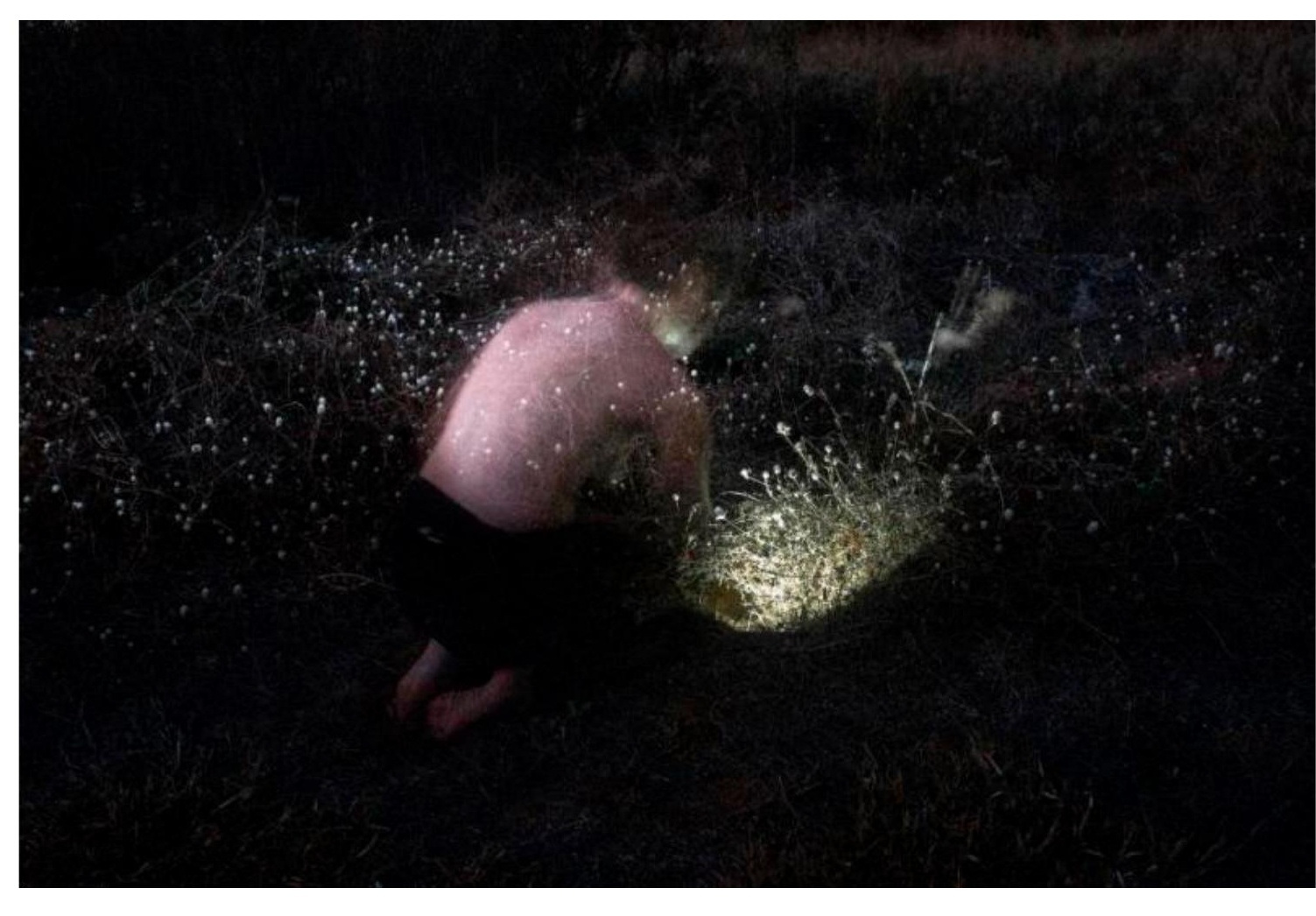

Figura 1

Daniela Paoliello

Escavar o escuro, 2020.

Fotografia. Díptico,

$70 \times 110 \mathrm{~cm}$ (cada)

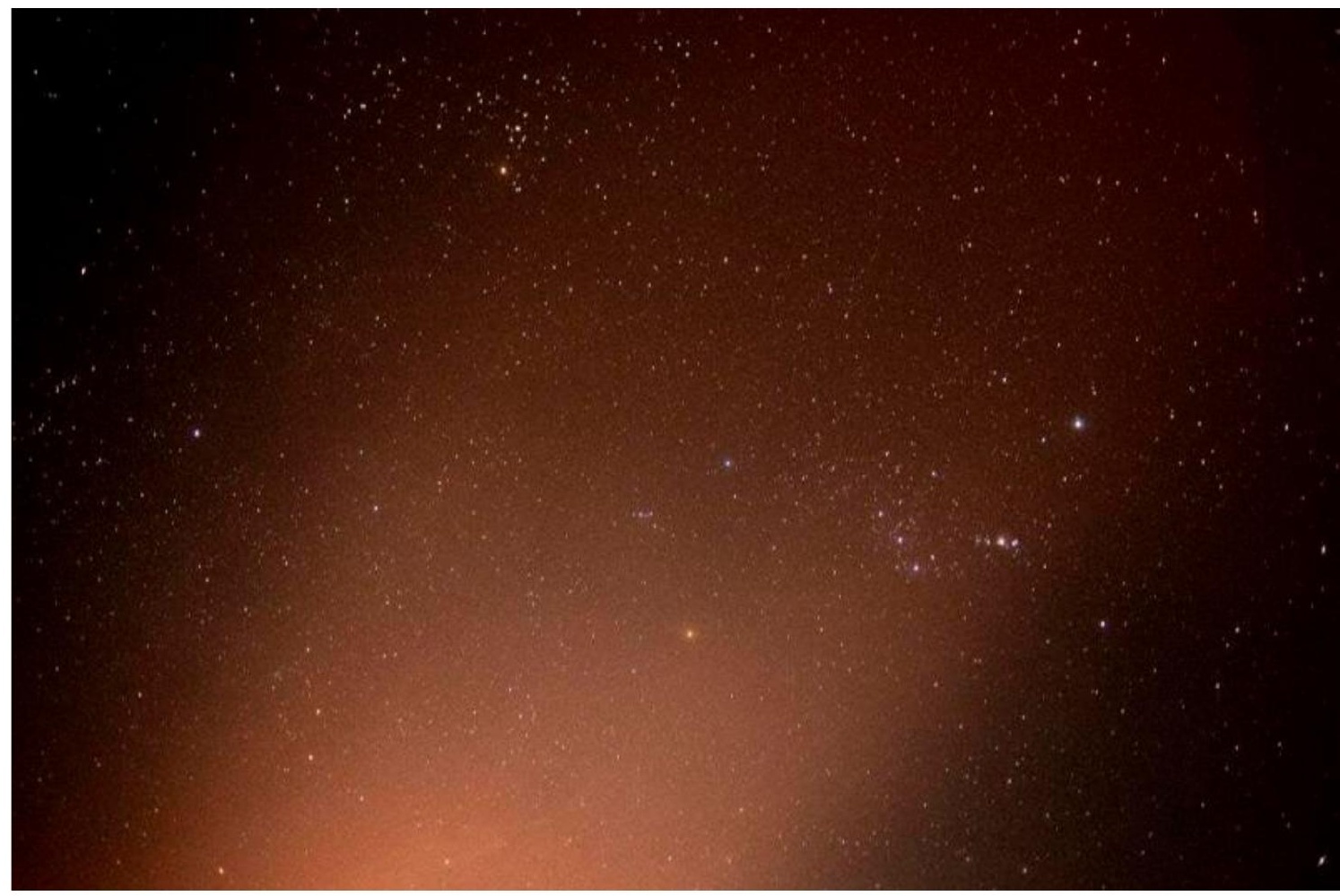


desativando nossa capacidade de ver, e assim produzindo o escuro. Ele se dá enquanto um fenômeno fisiológico, um "tipo de sensibilidade, uma atividade efetiva do olhar" (ENTLER, 2017). O escuro, portanto, toca e afeta o corpo em sua matéria, afirmando-se como elemento ativo dessa perda. Perda de visão, perda de coordenadas e referências espaciais.

A intenção experimental é, assim, intensificada pelo escuro e reforçada pela dependência do espaço e dos acontecimentos exteriores. Do movimento das marés, da força das ondas, da dificuldade de estabilizar o tripé, da intervenção que o movimento da água faz sobre o corpo e sobre a câmera. Reconhecer o espaço é fundamental, assim como observar o movimento dos elementos naturais enquanto forças externas que afetam o corpo. $O$ forte estouro das ondas que derruba o corpo das pedras, as correntes do mar, a presença habitual de escorpiões, o medo do homem intensificado pelo escuro. É nesse sentido que podemos inferir que no procedimento fotográfico é o corpo que, em sua árdua relação com o espaço, determina os limites da produção, que determina até onde é possível ir.

O procedimento seguia o rigor de retornar todos os dias, ritualmente, ao mesmo espaço nos mesmos horários (fim de tarde e noite), e produzir a partir de dois gestos: o de experimentação do espaço, que implicava em interferir no local, testar gestos, aplicar ideias preconcebidas ou esboçadas; e o de escuta e observação desse lugar. Exercitando uma escuta contemplativa, ou seja, uma escuta pelo olhar. A palavra contemplação, contemplatio, tem a mesma raiz etimológica do termo templum - templo -, se referindo, portanto, a um espaço de reconexão entre Deus e Homem, céu e terra. Espaço de suspensão de uma vivência discursiva do mundo, que dá abertura à experiência do sagrado. Podemos, como sugere Entler, pensar no espaço da contemplação como aquele que religa o olhar com uma dimensão invisível da realidade.

Merleau-Ponty observa essa capacidade de perceber o que nos cerca, como um processo que implica em dar significado àquilo que é captado pelos sentidos. Processo que seria capaz de produzir um reencontro entre a subjetividade e o mundo. A partir desse procedimento percebe-se uma série de pequenos eventos, "movimentos observados na paisagem - das folhas, das árvores, das nuvens, dos pássaros" (ENTLER, 2017).

O procedimento que constitui a série Escavar o escuro baseia-se em uma experiência operada/construída por meio de procedimentos planejados. Quer dizer, a "perda de si" não é parte de uma "espontaneidade improdutiva", desordenada, sem método. Ela é programada, disparada e possui diretrizes. 
Nesse ensaio as experiências foram estimuladas diariamente por dois meses, seguindo uma coordenada geográfica e temporal, a partir de escolhas intencionadas das matérias que vão integrar o trabalho, e da observação insistente e rigorosa do espaço. A escolha da luz exata que dura um curto intervalo de tempo, o estudo astrológico sobre a visibilidade do céu ou a incidência de luz lunar; a elaboração de gestos e sua repetição. Ou seja, a escolha precisa do território e dos elementos que vão potencializar a experiência faz parte dessa proposta metodológica.

O desejo mimético se faz presente em Escavar o escuro. Aqui o corpo é invadido pelo espaço que o circunda, pela água que vai e volta com o movimento da maré, pela textura da areia e das flores espinhentas que circundam os campos de hibisco. O desejo mimético nada mais seria que esse desejo de transferir a própria forma, os próprios limites, de se deixar ser invadido pelo espaço e tornar-se a si mesmo, paisagem, árvore, pedra, areia, mar. Desejo de semelhança, de romper com a forma e produzir uma dissolução, mesmo que imaginária, de si.

Se André Breton estava interessado em pensar no "possível da imaginação", Bataille em sua ruptura com o surrealismo propõe o "impossível do real" que abarcaria justamente essa dimensão dupla em que o trabalho surge com uma raiz fundadora no mundo, na realidade, e se desdobra em direção ao impossível, mas guarda sua origem na experiência real, física do mundo.

Na série, o corpo é confrontado em sua matéria e torna-se vaporoso, mistura-se com a água do mar, é erodido pelo brilho das escamas de peixe, pela luz da lua, pelo resto de luz que emana de uma pedra e pelos reflexos da água que reluzem o lusco fusco. O corpo aos poucos perde a própria verossimilhança, desfigura-se, se rendendo àquilo que Georges Bataille afirma ser uma vocação do corpo. Para o autor, a transgressão das formas não implicaria em desligar-se das mesmas, "reivindicar o informe não quer dizer reivindicar não-formas", mas antes abrir-se a laceração, a um processo que beira o sacrifício, mas que em sua negatividade, nesse processo de perda, inventa algo novo (MENEZES, 2020).

A "perda de si" opera aqui, de um lado, pela reconfiguração da experiência fotográfica, alienada daquilo que lhe é mais essencial: a visão. Nesse processo, o corpo desocupa seu lugar estabelecido de sujeito e passa a ser objeto do olhar, se oferece à visão, é desapossado de seu privilégio - daquele que vê -, e reinventa-se, portanto, a partir da sua condição de ser olhado. $E$ por outro lado, pela experiência direta do corpo na escuridão da natureza e no contato com as adversidades do espaço. 
Mas essa "perda de si" é também operada nesse dilaceramento imaginário do corpo, que se funde, se abre ao espaço, de modo que não apenas a semelhança em si, mas o desejo de semelhança toca e abre esse corpo, descolonizando a própria consciência, convertendo o olhar em uma experiência completa, orgânica que implica os outros sentidos e reintegra o olhar ao corpo (CUSICANQUI, Silvia, 2019).

Para Roger Caillois o desejo mimético acompanharia qualquer ser vivo e não seria um mecanismo de autopreservação podendo muitas vezes, até mesmo, colocar o ser em risco, definido pelo autor como um "luxo perigoso". O mimetismo seria uma função destinada, sobretudo, a uma operação estética capaz de realizar o fascínio pelo fora, um desejo de ceder à "tentação exercida pelo espaço", "lá onde tudo se coloca em questão e se decompõe". Onde o desconhecido nos toca, onde sujeito e objeto se interpenetram um no outro" (DIDI-HUBERMAN, 2015, p. 382), perturbando a dicotomia entre sujeito e objeto.

O autor sugere ainda, que poderíamos comparar a experiência mimética com a sensação de estar em um quarto escuro e perder a noção dos limites com o espaço. De sentir-se invadido pela densidade da escuridão e perder as referências. Ele adverte que a experiência da escuridão seria semelhante à possessão pelo espaço experimentada pelo sujeito no mimetismo. Ela seria capaz de tocar o indivíduo, envolvê-lo e atravessá-lo, e sobretudo, provocar a perda de suas referências. O espaço exerceria, portanto, uma sedução, uma hipnose sobre o ser, retendo-o e fazendo com que ele perca algo de si para obter equilíbrio entre o orgânico e o inorgânico (CAILLOIS, 1939, p.147).

Parece exercer-se aí o que o autor define como uma lei fundamental do universo em que as substâncias tendem à uniformidade. Se colocamos, por exemplo, um objeto quente em uma bacia com água fria, as temperaturas vão se equilibrar. $O$ espaço também atrairia o ser para uma uniformidade que pede dele a renúncia ao "domínio de si", ou seja "perder-se" para o meio. Nessa comunhão, o corpo experimenta sua semelhança substancial com a natureza, percebendo a ação das mesmas leis e a presença das mesmas estruturas.

O mimetismo nos permite ainda pensar em uma aproximação entre os seres, que não se sustenta necessariamente por uma semelhança realista experimentada na superfície do ser. Mas como um movimento que se dá também como gesto, como encenação, que pode acontecer apenas enquanto imagem projetada. Embora Caillois desenvolva sua teoria a partir do estudo do mimetismo animal, ele visa, de fato, o homem. 


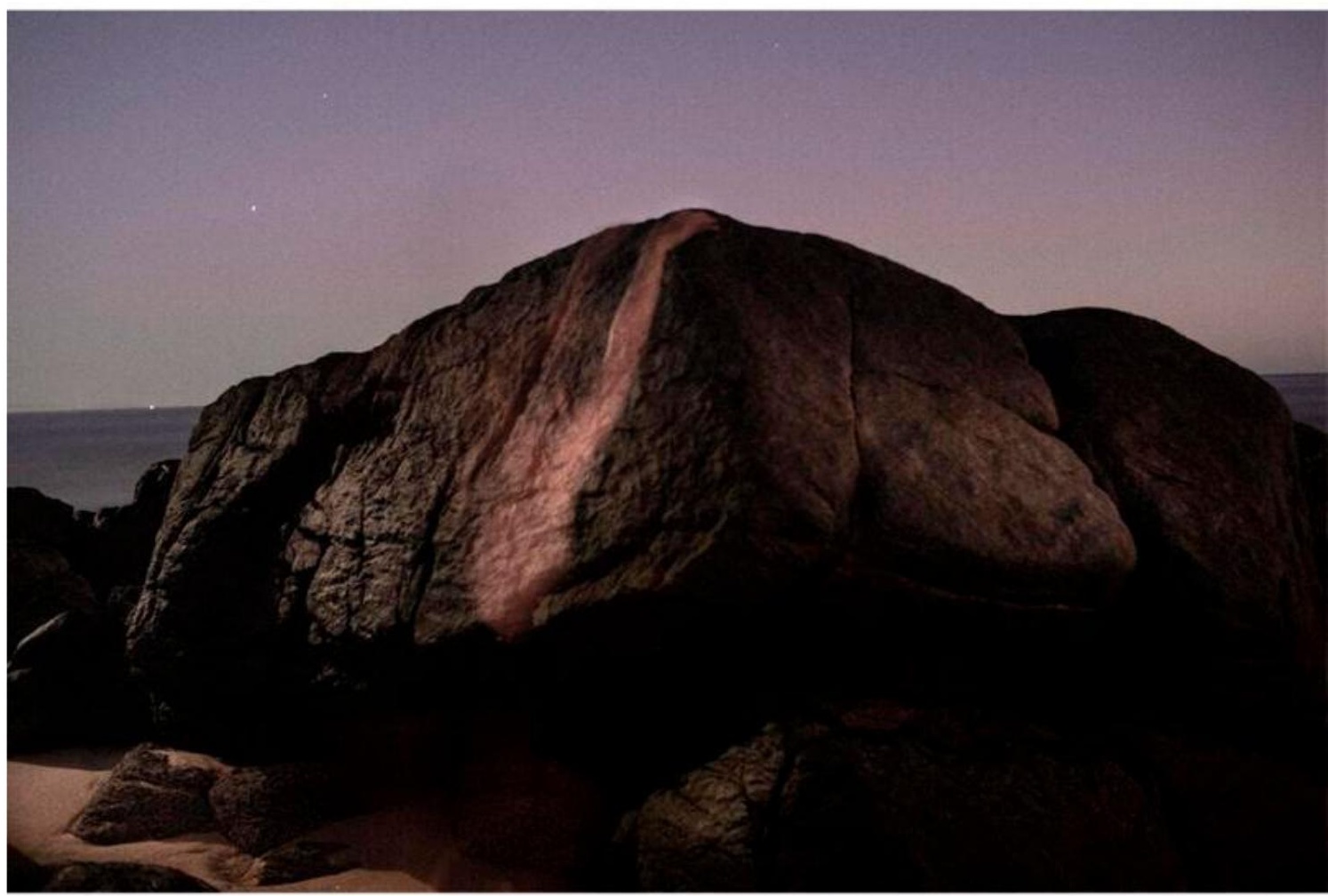

Figura 2

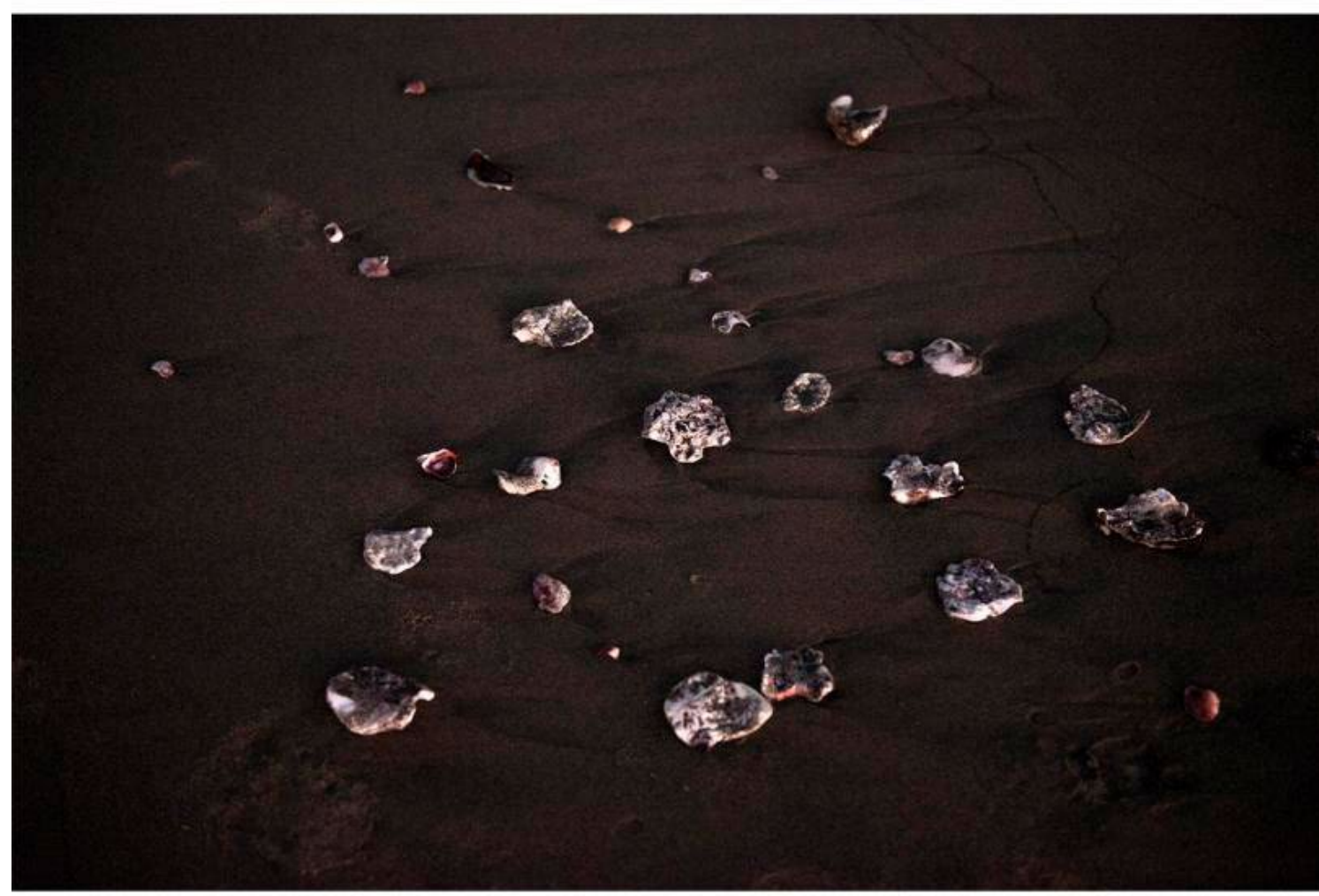

Fotografia Díptico

$70 \times 110 \mathrm{~cm}$ (cada) 
Em A máscara e a vertigem, Caillois expande o conceito de mimetismo definindo-o como uma estratégia de simulação teatral, e então chegamos a um ponto crucial: "o próprio ser é a máscara, a textura que se coloca sobre o ambiente” (MATA, Larissa Costa, ago./2015, p.108). A transformação mimética tem a propriedade de enganar o olhar e apresentar o corpo como pura imagem. Em Escavar o escuro observamos um corpo que se projeta sobre o ambiente, um corpo disseminado no espaço, que se espalha até sua dissolução, até tornar-se outro. Ele veste o espaço como uma máscara, um disfarce, que parece ser operado pelos resquícios de luz da noite que, como um furo, um rasgo no escuro, media o contágio de semelhança entre os corpos.

O conceito de magia contagiosa implicaria, segundo o antropólogo James Frazer, que as coisas que entram em contato continuam atuando umas sobre as outras, mesmo após apartadas. Portanto, ao vestir a pele de um animal ou realizar um ritual antropofágico, obtém-se por contágio o poder do ser vestido ou consumido, dado que "contato ou contágio" significa comunicação, em que o ser é capaz de se comunicar por qualquer uma de suas partes. Ambas as formas de magia exigem para sua eficácia que exista um contato, seja ele literal ou metafórico (simbólico). Frazer explica:

\footnotetext{
Ambos os ramos da magia, o homeopático e o contagioso, podem ser incluídos convencionalmente sob a denominação geral de magia simpática, já que ambos supõem a possibilidade de interação entre coisas que estão distantes umas das outras, através de uma simpatia secreta, sendo o impulso transmitido de uma a outra por meio do que poderíamos conceber como um éter invisível, não muito diferente do que é postulado pela moderna ciência com um objetivo precisamente igual, ou seja, explicar como as coisas podem afetar fisicamente umas às outras através de um espaço que parece estar vazio. (FRAZER, James. 1982, p. N/A.)
}

Podemos pensar aqui que Caillois trava uma relação com essas ideias, tendo ele mesmo recorrido a Frazer e ao conceito de magia para entender o mimetismo. Em Escavar o escuro, a paisagem, as plantas, o solo, as pedras, a água do mar parecem exercer essa força de contágio, despertando no corpo seu desejo mimético. O mimetismo é justamente essa potência de duas coisas se afetarem a partir de uma força invisível, de modo que no momento em que o corpo imita uma pedra - magia imitativa/homeopática - ele se transmuta nela mesma, ou que ao envolver-se de folhas, cobrir-se de areia - magia por contágio - ele adquire suas qualidades. É através de um contato que o corpo se desfigura, em um contágio perturbador, uma "laceração que passa por contato" (DIDI-HUBERMAN, 2015, p. 39).

No trabalho de Marise Maués, artista Paraense, observamos certo desejo mimético, de transbordar no espaço ou ser por ele invadido. Na sequência de fotos abaixo (Figura 4) vemos sua performance intitulada Loess, ação feita 


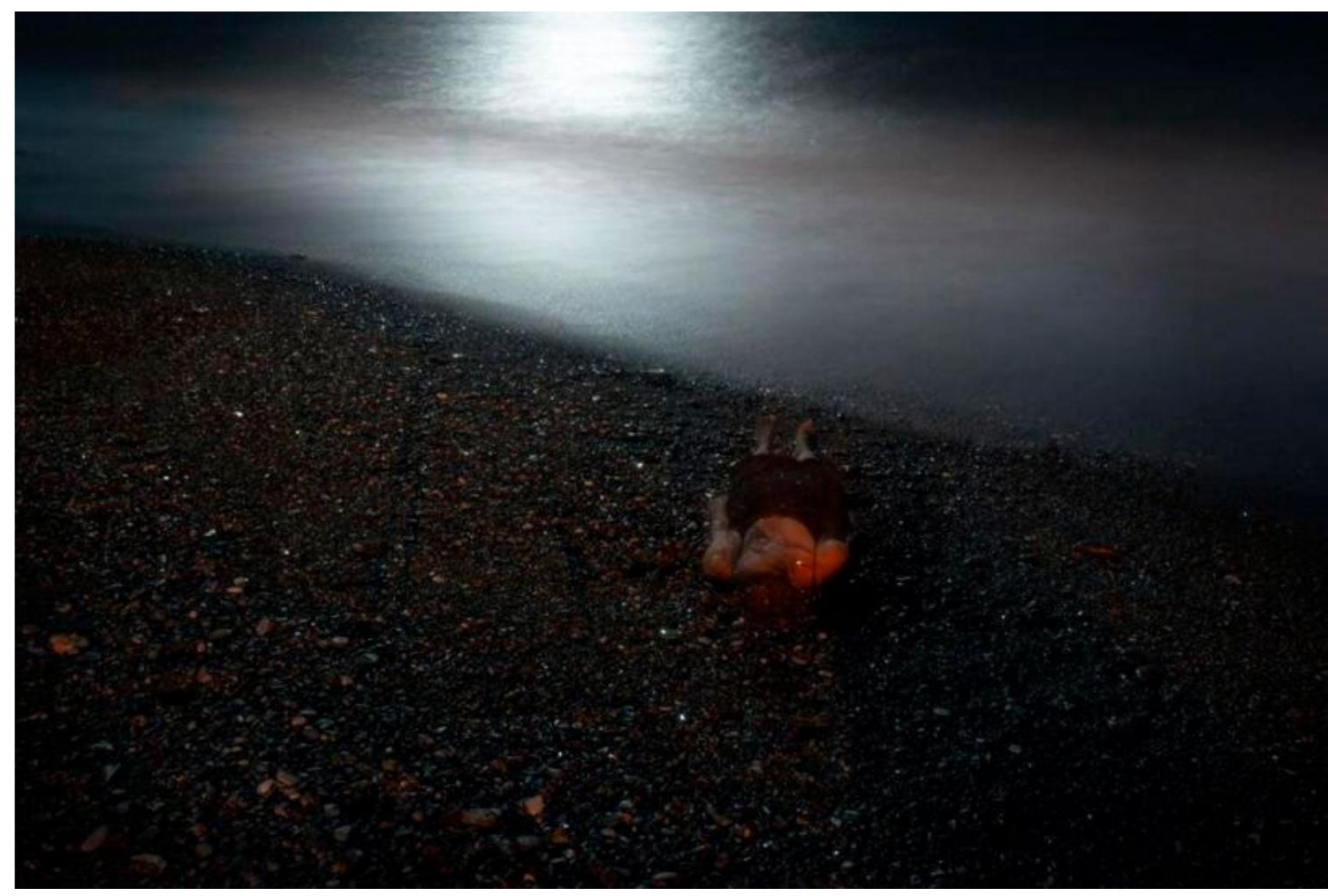

Figura 3

Daniela Paoliello

Escavar o escuro, 2020.

Fotografia, Díptico,

$70 \times 110 \mathrm{~cm}$ (cada) 
exclusivamente para a câmera, e registrada através do recurso de timelapse. A artista se instala em um leito de igarapé e lá permanece inerte por sete horas seguidas, tempo em que o volume de água do rio sobe até quase cobrir seu corpo por completo e então volta a esvaziar até seus pés. Marise usa um vestido branco e longo, que, ao fim da performance evidencia as marcas da natureza somando-se aos rastros deixados em sua pele. Experimenta as intensidades específicas daquele espaço: as mudanças na temperatura, a presença de outros corpos, as oscilações de luz e de vento, os sons que se alteram de acordo com o passar do dia. Marise aceita perder-se para criar, para reinventar-se. Ela perde a segurança, o conforto, e sua própria respiração que se extingue junto ao ápice do volume das águas, e então retorna dessa experiência marcada, potente, outra. Testa os limites do próprio corpo, que vai se adensando de camadas sobrepostas com o passar do tempo; perde e ganha, destrói e cria a cada movimento que a trespassa. É dessa experiência que nasce a imagem.

A experiência da "perda de si" é aqui disparada intencionalmente e acontece dentro de alguns parâmetros, inclusive o cálculo de quanto tempo leva até que o rio atinja seu rosto. No entanto, o fator de risco e descontrole, a exaustão e o desconforto que seguem durante a performance constituem essa experiência de perda, deslocamento e autoperturbação. Há um rigor na perda. É nesse sentido, que "fazer sem dominar e sem controlar não poderia ser entendido como equivalente a fazer sem trabalho."7 Como observa Priscilla Menezes:

(...) ainda hoje, ao abordar esse aspecto incontrolável do fazer artístico, há um tipo de resistência relacionada à ideia de que um artista que não se esforça para dominar o próprio fazer estaria trabalhando através de um espontaneísmo sem rigores e tensões e, por isso, indigno de reconhecimento. Entretanto, muitos dos artistas que admitem criar negociando com forças externas a si afirmam que essa experiência inclui uma espécie de susto que os convoca a uma trabalhosa investida no desconhecimento de si. ${ }^{8}$

Bataille sugere que o desvio na forma se daria através da comunicação - aquilo que é capaz de abrir o ser - ou seja, a partir de um contato alterante com outra matéria. Didi-Huberman observa ainda que, para Bataille, a matéria "não é algo fixo, mas oscilante, elemento não estável, é tudo que claudica na ideia a ser feita do mundo e de nós mesmo" (DIDI-HUBERMAN, 2015, 

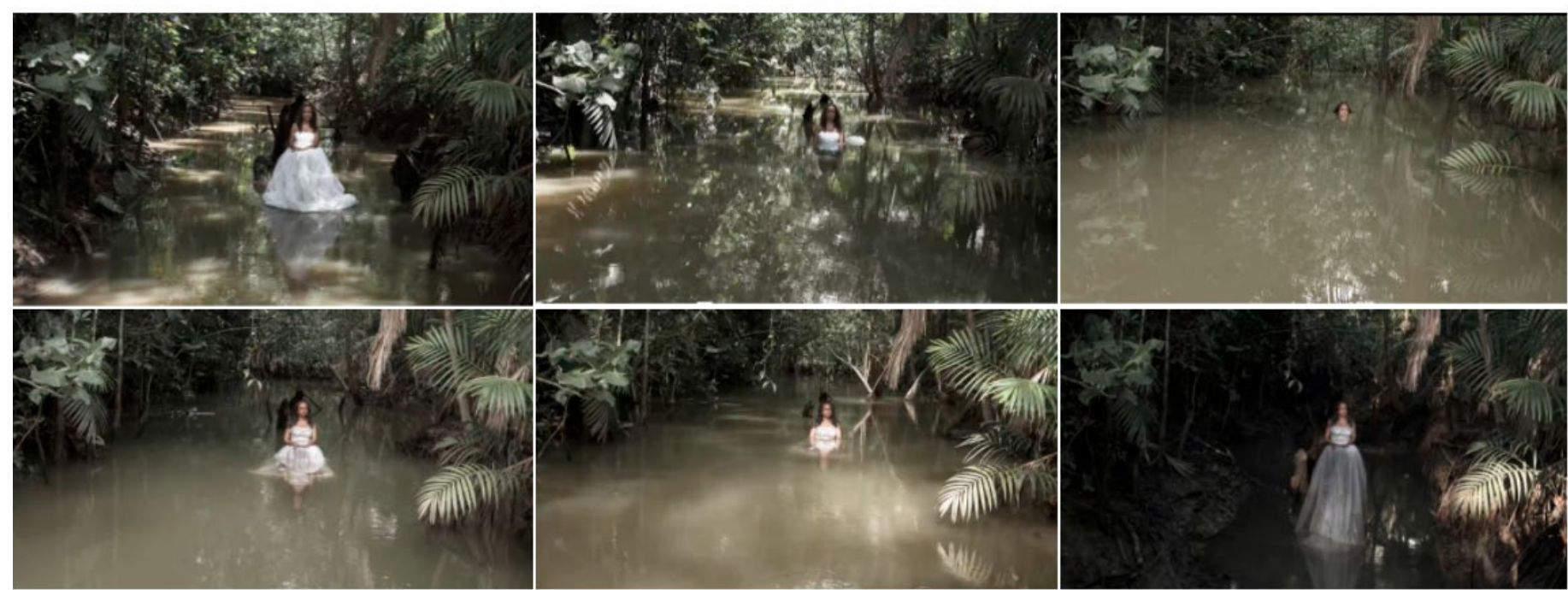

Figura 4

Marise Maués Loess, 2013. Still de vídeo. Fonte: Diário

Contemporâneo, disponível em: http:// www.diariocontemporaneo.com.br/tag/ marise-maues/ Acesso em: 05 dez. 2020 p. 297). A estabilidade e a substancialidade do corpo é, portanto, abalada ao entrar em contato com outra matéria: "Transgredir as formas seria, em primeiro lugar, transgredir as formas seculares do antropomorfismo" (DIDIHUBERMAN, 2015, p. 50).

A transgressão das formas, porém, não se resume em Bataille apenas à transgressão dos limites ultrapassados, mas também está ligada ao gesto de mover, deslocar limites, rebaixá-los, uni-los em outros pontos precisos, onde não eram esperados.

Se para Bataille, o deslocamento das formas desloca também o pensamento, apesar da dilaceração do corpo ser aqui imaginária, podemos afirmar que ela produz um abalo, uma perda, um deslocamento real. É nesse sentido que Didi-Huberman afirma que "os desvios da natureza só podem, como formas, desconjuntar nosso pensamento" (DIDI HUBERMAN, 2015, p.235).

\footnotetext{
Ora, se temos que entender por alteração o processo pelo qual uma forma é transformar em outra - deformada, condenada, ainda que por um instante apenas à decomposição, ao informe -, temos também que reconhecer nessa alteração o próprio trabalho da forma, e na palavra desvio, uma espécie de definição cristalizada da própria forma, considera em sua economia, em sua dinâmica, em seu jogo ou em seu trabalho do negativo (DIDI HUBERMAN, 2015, p.295).
}

Em Escavar o escuro uma matéria "toca - ataca, infecta - a outra", produzindo uma espécie de colagem, uma transferência operada pela luz que depõe os elementos e transgride, desfigura a forma, e na "reciprocidade dilacerante do olhar, em que toda forma decisiva olha seu espectador, abraçando-o, por assim dizer, num movimento de perda e de fora de si" (DIDI HUBERMAN, 2015, p.368). 


\section{Considerações finais}

A "perda de si" é invocada em Escavar o escuro na exposição do corpo ao mecanismo fotográfico, na relação com a natureza, com o espaço. Partindo de um "ateliê terrestre", de modo que é o contato com a exterioridade material o motor de um descentramento de si, que se dá tanto no processo de produção e experimentação, como na sua colocação em forma pela "projeção de uma perda de si na imagem" (DIDI-HUBERMAN, 2015, p. 382).

A perda é operada a partir de uma confrontação do corpo que desloca o pensamento ao lançar esse corpo no escuro da noite e no desconforto do mundo natural. Observamos, assim, como a "perda de si" enquanto método, que parte de uma intencionalidade de deslocamento, pode ser aplicada em processos criativos que envolvem a fotografia.

A fotografia figura como mediadora da experiência, mas, mais que isso, como responsável pelo acontecimento. Ela é o motivo desencadeador das experiências de perda, uma vez que incita o corpo a se mover por esses espaços. Ela é o ponto fixo do movimento de descontrole.

A "perda de si" é sobretudo uma proposição. Um método que contraria a própria noção de controle que qualquer metodologia carregaria a princípio. Ela é, por sua própria condição, dilacerante, um conceito em aberto, em construção. Mas sobretudo, ela é uma postura diante do mundo e de si, postura que invoca a própria derrisão. Opera a partir de uma dupla posição: a de colocação em crise do pensamento e a de colocação em crise do corpo. Um repercutindo, abalando o outro. Trata-se de um desencadeamento controlado de acidentes, de crises e transgressões. É a negação sistemática do "domínio de si", postura que se estabelece de forma dominante em uma sociedade fundada - violentamente - sobre o racionalismo científico.

Intencionou-se neste artigo propor o conceito da "perda de si" e demonstrar possíveis aplicações para, por um lado, desencadear o ato criativo e, por outro, instrumentalizar uma chave para a aproximação crítica de obras contemporâneas, sobretudo aquelas que envolvem o processo fotográfico.

Citando Didi-Huberman: "É essa, portanto, a atitude decisiva: nada fixar, não se satisfazer com nenhuma tese, nenhum resultado, nenhuma síntese" (DIDIHUBERMAN, 2015, p. 371). Ou seja, manter a fragilidade e o inacabamento, manter a natureza do conceito, sustentando a intencionalidade da perda de si enquanto projeto ético, estético e político. 


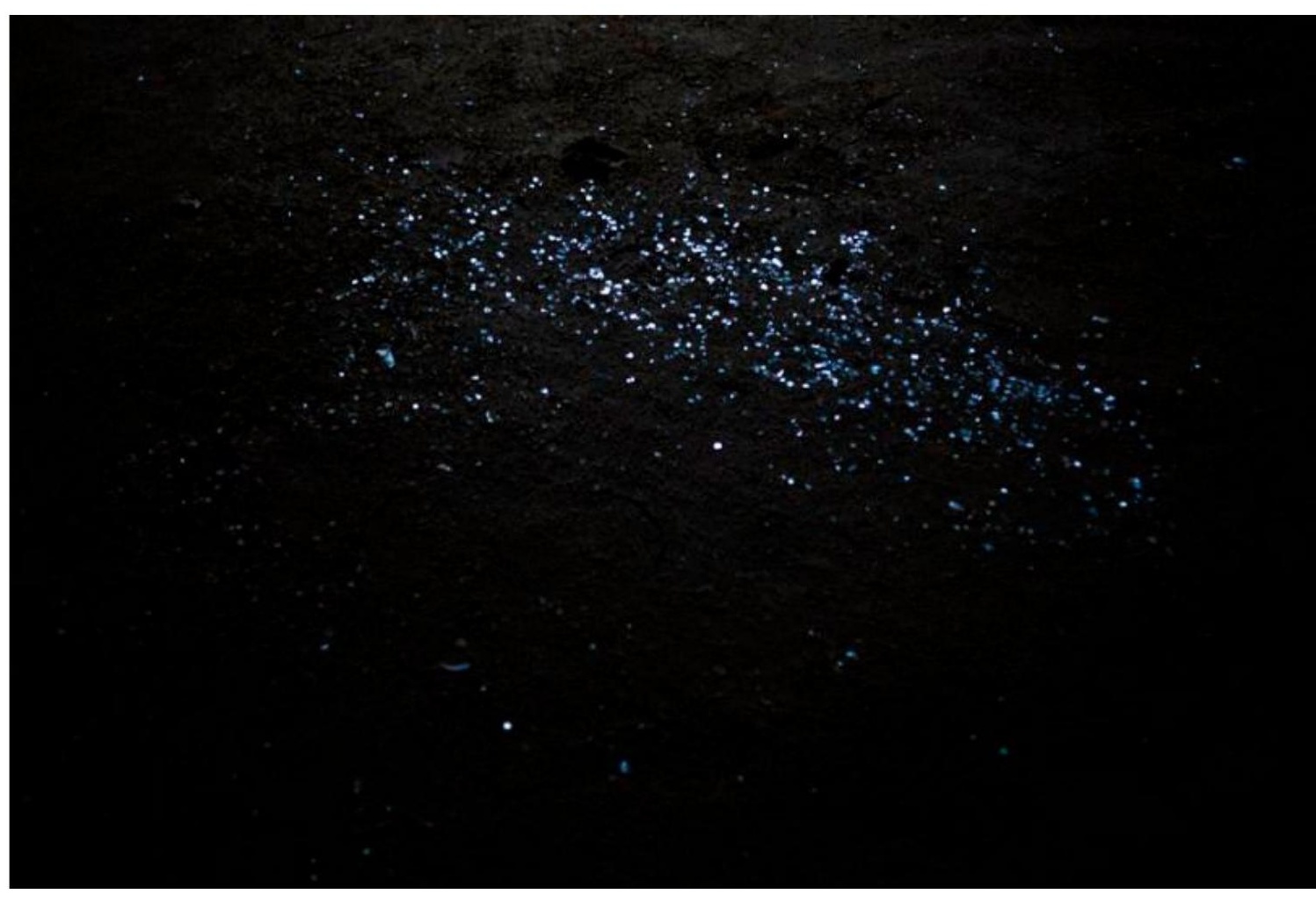

Figura 5

Daniela Paoliello

Escavar o escuro, 2020.

Fotografia Díptico,

$70 \times 110 \mathrm{~cm}$ (cada)

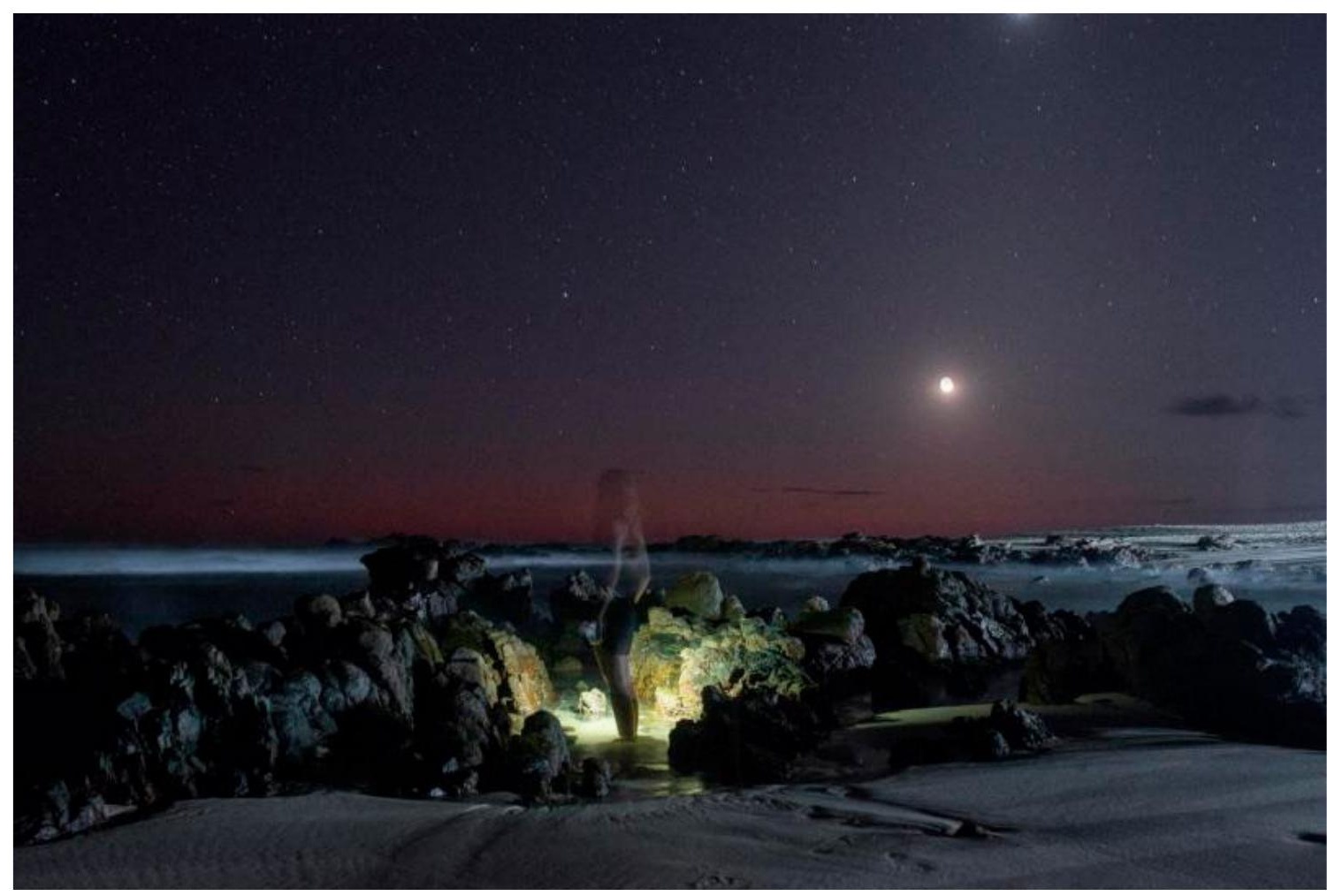


Sustentar na imagem um perigo. Trata-se aqui do artista brincando de "colocar medo em si mesmo", movido por uma "vontade de chance, vontade de arte, vontade de inacabamento" que coloca o ser em movimento (DIDIHUBERMAN, 2015). Sustentando a perda como produtora de imagem. Se fazendo marcar para se fazer abrir.

\section{Referências}

ARTAUD, Antonin. A perda de si: cartas de Antonin Artaud. Rio de Janeiro: Rocco, 2017.

BATAILLE, Georges. A parte maldita precedida de "a noção de dispêndio". Belo Horizonte: Editora Autêntica, 2013.

. Sobre Nietzsche: vontade de chance. Belo Horizonte:

Autêntica Editora, 2017.

BISHOP, Claire. Artificial hells: Participatory art and the politics of spectatorship. Verso Books, 2012.

BRESSON, Henri Cartier. L'instant Decisif, Images à la sauvette, 1952.

CAILLOIS, Roger. Mimetismo y Psicastenia Legendaria. IN El mito y el hombre. Buenos Aires: Sur Buenos Aires, 1939.

CUSICANQUI, Silvia, 2019 [entrevista na internet] Disponível em: https://alicenews.ces.uc.pt/?lang=1\&id=23864. Acesso em: $12 \mathrm{mar}$ 2020.

DIDI-HUBERMAN, Georges. A semelhança informe: ou o gaio saber visual segundo Georges Bataille. Rio de Janeiro: Contraponto, 2015.

ENTLER, Ronaldo. Poéticas do acaso: acidentes e encontros na criação artística. 2000, 203 f. Tese (Doutorado em Artes) Escola de Comunicações e Artes, Universidade de São Paulo, SP, 2000.

Religações: o escuro da fotografia contemporânea. [artigo na internet]. Icônica, 2017. Disponível em: http://www.iconica.com.br/ site/religacoes-o-escuro-da-fotografia-contemporanea/ Acesso em 15 mar. 2020.

FEDERICI, Silvia. Calibã e a bruxa. Mulheres, corpo e acumulação primitiva. Rio de Janeiro: Editora Elefante, 2017.

FLORES, Lívia; SOMMER, Michelle. Derivas acadêmicas em pós-graduação em artes na cidade do Rio de Janeiro. Revista Poiésis, Niterói, v. 20, n. 33, p. 217-236, jan/jun. 2019. 
FLORES, Livia; SOMMER, Michelle. Desilha em três vistas. Cadernos Desilha 2. Rio de Janeiro: Programa de Pós-Graduação em Artes Visuais (PPGAV-EBA-UFRJ) Editora Circuito, 2019.

FONTCUBERTA, Joan. O beijo de Judas: fotografia e verdade. Ed.Gustavo Gili, SL. Barcelona, 2010. . A câmera de Pandora: a fotografi@ depois da fotografia. São Paulo: G. Gili, 2012.

GOLDMAN, Marcio. Jeanne Favret-Saada, os afetos, a etnografia. In cadernos de campo n.13 2005 In Cadernos de Campo n 13. 2005 Revista dos Alunos de Pós-Graduação em Antropologia Social da USP.

HERKENHOFF, Paulo. Rodrigo Braga - um modo de ver. [artigo na internet] Rio de Janeiro, 2011 Disponível em : http://www.rodrigobraga. com.br/texts. Acesso em 15 jul. 2016.

KIFFER, ANA in ARTAUD, Antonin. A perda de si: cartas de Antonin Artaud. Rio de Janeiro: Rocco, 2017.

LEIRIS, Michel. A África fantasma. São Paulo: Cosac Naify, 2007.

MATA, Larissa Costa. Mimetismo e metamorfose. Revista do Instituto de Estudos Brasileiros, Brasil, n. 61, ago. 2015.

MENEZES, Priscilla. Outra para si In Exílio. São Paulo: 2015.

Coagular o mundo: arte, magia e cura. [artigo da internet] A palavra solta, 2020. Disponível em https://www. revistaapalavrasolta.com/post/coagular-o-mundo-arte-magia-e-cura?f bclid=IwAR2el9xFuNV5nx6lx70wtSwhrwjbcm7Xsl3izqw0whVyb402_ Z76R7NDaWU. Acesso em: 01 out 2020.

PAOLIELLO, Daniela. A "perda de si" na descolonização do processo contemporâneo de produção fotográfica. Arte e Ensaios, Rio de Janeiro, PPGAV-UFRJ, vol. 26, n. 40, p. 141-153, jul./dez. 2020. ISSN-2448-3338. DOI: https://doi.org/10.37235/ae.n40.10. Disponível em:<http:// revistas.ufrj.br/index.php/ae>

PONTES, Thais Graciotti. Viagem a um arquipélago possível: $O$ artista viajante em processo. Tese (Doutorado em Artes) Programa de PósGraduação em Artes. Universidade do Estado do Rio de Janeiro, RJ, 2018.

PONTY, M. Merleau. O visível e o invisível. São Paulo: Editora Perspectiva, 2003.

Artigo recebido em 29 de junho de 2021 e aceito em 04 de agosto de 2021.

Este é um artigo publicado em acesso aberto sob uma licença Creative Commons (cc) BY 